\title{
Pengelolaan Informasi Kesehatan Secara Terintegrasi untuk Memaksimalkan Layanan Kesehatan kepada Pasien di Rumah Sakit
}

\author{
Nuzlil Laily Nur Azizah ${ }^{1}$, M. Very Setiawan ${ }^{2}$ \\ ${ }^{1}$ Fakultas Farmasi Universitas Padjadjaran, Sumedang Jawa Barat, Indonesia \\ ${ }^{2}$ Fakultas Sekolah Pascasarjana, Universitas Gadjah Mada, Sleman, Yogyakarta, Indonesia
}

\begin{abstract}
Abstrak
Banyaknya masyarakat yang memperoleh perawatan pada beberapa instansi layanan kesehatan menjadikan adanya alasan mengenai pentingnya kegiatan pengelolaan informasi kesehatan pasien yang terintegrasi. Hal ini berfungsi untuk menyediakan informasi kesehatan secara komprehensif kepada pasien dan staf medis dalam membantu pelayanan kesehatan yang lebih baik. Artikel ini mengkaji elemen-elemen yang diperlukan dan model dalam kegiatan Health Information Management yang terintegrasi. Kajian artikel ini dilakukan secara deskriptif dengan mengkaji 23 literatur yang terbit dari tahun 2007-2017, yang diperoleh dari jurnal-jurnal yang dilanggan perpustakaan UGM, Google Scholar dan PubMed Health, mengenai pengelolaan informasi kesehatan pasien. Hasil penelitian ini menjelaskan bahwa elemen yang diperlukan dalam penerapan Health Information Management yang terintegrasi dapat dibagi ke dalam lima elemen, yaitu: 1. Sumber Daya Manusia, 2. Kebijakan dan kelembagaan, 3. Penerapan sistem, 4. Data dan pengelolaannya, 5. Akses dan integrasi data. Pada model pengelolaan informasi kesehatan pasien yang terintegrasi, harus menyediakan akses terhadap informasi kesehatan pasien dan memungkinkan pertukaran data yang dikelola beberapa petugas medis, pengelola data pasien dan rumah sakit lain. Hal ini didukung oleh sebuah sistem informasi kesehatan yang dilengkapi dengan sistem keamanan data dan adanya dukungan dari kepala rumah sakit.
\end{abstract}

Kata kunci: Pengelolaan informasi kesehatan; layanan kesehatan di rumah sakit; integrasi informasi kesehatan pasien

\section{Integrated Health Information Management to Maximize Health Services to Patients in Hospitals}

\begin{abstract}
The large number of people who receive care in some healthcare establishments make sense of the importance of integrated patient health information management activities. This serves to provide comprehensive health information to patients and medical staff to help better health care. This article examines the necessary elements and models in integrated Health Information Management activities. The review of this article was conducted descriptively by reviewing 23 literatures published from 2007-2017, obtained from journals subscribed to UGM libraries, Google Scholar and PubMed Health, on the management of patient health information. The results of this study explain that the elements needed in the application of integrated Health Information Management can be divided into five elements, namely: 1. Human Resources, 2. Policies and institutions, 3. Implementation of the system, 4. Data and its management, 5. Access And data integration. In an integrated patient health information management model, it must provide access to patient health information and enable the exchange of data managed by some medical officers, managers of patient data and other hospitals. This is supported by a health information system equipped with a data security system and support from the head of the hospital.
\end{abstract}

Key words: Health information management; Health services in hospitals; Integration of patient health information 


\section{Pendahuluan}

Banyaknya masyarakat yang saat ini memperoleh perawatan pada beberapa instansi layanan kesehatan, menjadikan adanya alasan pentingnya kegiatan Health Information Management (HIM). Hal ini karena seseorang mungkin melakukan pemeriksaan kesehatan pada rumah sakit di kota lain atau melakukan pengobatan ke luar negeri. ${ }^{1}$

Gagasan mengenai pengelolaan informasi kesehatan pasien sebenarnya bukan merupakan hal baru. Di sekitar kita banyak instansi pelayanan kesehatan yang telah melakukan pengelolaan informasi kesehatan pasien dengan menyimpan data hasil lab, arsip-arsip tentang pengobatan dan lain sebagainya. ${ }^{2}$ Namun data tersebut hanya dikelola pada masing-masing instansi dalam bentuk record konvensional berbasis kertas. $^{3}$

Perkembangan teknologi memberikan banyak kontribusi untuk meningkatkan pelayanan kesehatan yang diberikan kepada pasien secara lebih efektif. $^{4}$ Termasuk dalam kegiatan pengelolaan informasi kesehatan, beberapa instansi layanan kesehatan mulai menerapkan sistem informasi kesehatan secara elektronik agar pengelolaan data kesehatan pasien dapat dilakukan secara lebih efektif. Beberapa rumah sakit juga telah melakukan alih media data kesehatan pasien dari bentuk kertas ke format digital. $^{2}$ Mereka juga mulai membuat catatan Electronic Health Record (EHR) yang berisi data demografi pasien, riwayat medis dan obat-obatan, informasi diagnostik, tanda vital, riwayat kesehatan, data laboratorium, dan laporan radiologi. ${ }^{1}$ Yang disayangkan yaitu informasiinformasi tersebut belum dapat terbuka untuk dapat diakses lembaga pelayanan kesehatan lain, karena sistem pengelolaan informasi kesehatan pasien hanya dilakukan secara mandiri, pada masingmasing instansi layanan kesehatan. ${ }^{5}$

Health Information Management sebenarnya bertujuan untuk mengumpulkan, menyimpan dan membuat informasi kesehatan pasien tersedia dan mudah diakses saat dibutuhkan. Sihingga HIM dapat membantu para petugas pelayanan kesehatan dalam memberikan pelayanan kesehatan kepada pasien secara lebih baik. ${ }^{1}$ Atas dasar ini adanya pengelolaan informasi kesehatan pasien yang terintegrasi merupakan hal yang penting, agar dapat memfasilitasi beberapa penyedia layanan medis dalam kegiatan pertukaran dan berbagi informasi kesehatan pasien. ${ }^{5}$

Seperti yang disampaikan oleh WHO bahwa sistem kesehatan elektronik harus dibangun untuk memfasilitasi pertukaran data. ${ }^{1}$ Selain itu informasi kesehatan pasien yang tersedia harus dapat dilayankan dengan sebuah sistem informasi, agar orang yang membutuhkan tidak perlu datang secara langsung ke tempat instansi pengelola data. ${ }^{3}$ Dengan adanya sistem informasi kesehatan yang menyediakan akses data pasien dalam format digital, diharapkan memungkinkan petugas medis melacak data pasien dari waktu ke waktu, membantu mengetahui bagaimana keadaan pasien dan meningkatkan kualitas pelayanan kesehatan. ${ }^{6}$ Sehingga dengan pengelolaan informasi kesehatan pasien yang dilakukan secara elektronik dan terintegrasi, dapat membantu setiap petugas pelayanan kesehatan dalam memberikan kegiatan pelayanan kesehatan kepada pasien secara lebih baik. ${ }^{2}$

Atas dasar ini penulis ingin mengkaji elemen-elemen yang diperlukan dan model dalam kegiatan Health Information Management yang terintegrasi.

\section{Metode}

Kajian artikel ini dilakukan secara deskriptif dengan mengkaji beberapa literatur terdahulu mengenai pengelolaan data dan informasi kesehatan pasien. Pengumpulan literatur dilakukan melalui pencarian dari jurnal-jurnal yang dilanggan perpustakaan UGM, Google Scholar dan PubMed Health. Jurnal yang dipilih hanya jurnal berbasa inggris yang 
diterbitkan pada 10 tahun terakhir, yaitu tahun 2007-2017. Proses pencarian literatur dilakukan menggunakan metode "boolean logic" dengan menambahkan kata "and" untuk menggabungkan masingmasing kata kunci. Kata kunci yang digunakan dalam pencarian yaitu "health information management" and "electronic" and "system" and "patient" and "hospital" and "integrated". Secara keseluruhan literatur yang muncul pada proses pencarian berjumlah 5.185 , namun yang menurut penulis relevan dengan topik bahasan artikel ini hanya berjumlah 38 .

Dari 38 literatur yang terkumpul, penulis mengkaji 23 literatur yang membahas mengenai elemen-elemen yang diperlukan dan model dalam pengelolaan informasi kesehatan pasien yang terintegrasi.

\section{Hasil}

\section{Elemen dalam kegiatan Helath Information Management (HIM) yang terintegrasi}

Artikel ini mengkaji 23 literatur yang membahas mengenai Health Information Management, Medical Record Management, Elektronik Health Record atau tema lain berkaitan dengan pengelolaan data atau informasi kesehatan pasien. Penjelasan dari hasil penelitianpenelitian tersebut yaitu:

Penelitian Carroll dkk yang membahas mengenai penerapan Elektronik Helath Record (EHR) untuk membantu memberikan perawatan kesehatan kepada pasien secara lebih baik. EHR diharapkan dapat memfasilitasi pertukaran informasi kesehatan pasien di beberapa penyedia layanan kesehatan. Menurut Carroll dkk elemen yang harus ada pada penerapan EHR yaitu: 1. Adanya portal untuk menyediakan akses informasi kepada pengguna, 2. Adanya pimpinan instansi yang mendukung implementasi EHR, 3. Adanya keterlibatan staf medis dalam Implementasi EHR, 4. Adanya pelatihan untuk staf pengelola EHR, 5. Adanya penggabungan data dari setiap rumah sakit. ${ }^{7}$ Cludia dkk, menjelaskan elemen penting dalam kegiatan EHR yaitu: 1. Privasi dan keamanan, 2. Pemilihan model sistem informasi yang dapat mewakili sistem yang digunakan di setiap rumah sakit, 3. Staf dan organisasi untuk semua rumah sakit. ${ }^{8}$ Pada penelitian Ashish dkk yang mengkaji pemanfaatan Health Information Technologi dalam membantu pelaksanaan EHR dan pertukaran informasi kesehatan pasien, harus memperhatikan: 1. Bagaimana penerapan EHR di rumah sakit dan 2. Bagaimana EHR memfasilitasi pertukaran informasi kesehatan pasien. $^{9}$

Menurut Stephen and Jeffrey hal yang perlu diperhatikan untuk dapat menciptakan inovasi sistem informasi kesehatan elektronik yaitu: 1. Aplikasi IT untuk menunjang kegiatan EHR, 2. Kebijakan, seperti siapa saja yang dapat melakukan proses input data atau kebijakan dalam penggunaan data. ${ }^{10}$ Esther Suter dkk yang menjelaskan 10 elemen kunci untuk menyediakan sistem informasi kesehatan kepada pasien. Hal yang harus diperhatikan yaitu: 1. Layanan yang komprehensif yang terintegrasi, 2. Layanan yang berorientasi pada pasien dan dapat memenuhi kebutuhan informasi pasien, 3. Cakupan geografis pasien untuk dapat melakukan akses terhadap informasi, 4. Standar pengiriman data antar lembaga kesehatan, 5. Adanya standar format data yang digunakan, 5. Kemampuan pengelolaan sistem, 6. Sistem informasi, 7. Dukungan pimpinan, 8. Petugas medis yang terintegrasi, 9. Integrasi dari instansi pelayanan kesehatan, 10. Pengelolaan anggaran. ${ }^{11}$

Jennifer dkk menjelaskan dalam pelaksanaan Personal Health Records (PHR) yang terintegrasi, hal yang diperlukan yaitu: 1. Data medis elektronik, 2. Akses untuk pasien 3. Adanya proses berbagi data. ${ }^{12}$ Penelitian Hussain mengenai penerapan Health Information Exchance (HIE) untuk membantu meningkatkan kualitas layanan yang diberikan rumah sakit, menjelaskan 
elemen yang diperlukan yaitu: 1. Staff medis (farmasi, lab, radiologi) untuk membantu mengumpulkan data, 2. Sistem pengelolaan informasi, 3. Adanya pertukaran informasi. ${ }^{13}$ Penelitian Oliver dkk yang mengkaji implementasi dari Regional Health Information Network (RHIN) menyatakan komponen yang harus dipenuhi yaitu: 1. Sistem informasi pada layanan kesehatan yang terintegrasi, 2 . Elektronik health record, 3. Akses data yang disediakan untuk pasien, 4. Kebijakan privasi data pasien. ${ }^{14}$ Sedangkan untuk memberika akses terhadap data secara efektif menurut Dean dkk rumah sakit dapat menyediakan: 1. Akses data menyeluruh kepada pasien, 2. Informasi dalam bentuk ringkasan yang mudah dipahami. ${ }^{15}$ Menurut James hal ini dapat didukung dengan adanya: 1. Hardware sebagai pendukung sistem informasi, 2 . Software untuk kegiatan, 3. Perubahan pengelolaan dari pengelolaan konvensional beralih ke pengelolaan secara elektronik. ${ }^{16}$

Penelitian Muhammad dan Moazzam mengenai sistem informasi kesehatan rumah sakit di Pakistan memerlukan komponen-komponen: 1. Kebijakan dan perencanaan penerapan sistem, 2 . Pengelolaan informasi, 3. Adanya tranmisi perubahan format data yang sesuai sistem, 3. Sistem informasi kesehatan yang terintegrasi. ${ }^{17}$ Vincent dkk menambahkan, selain sistem informasi hal yang perlu dipersiapkan dalam kegiatan Health Information Management Sistem yaitu: 1. Adanya pelatihan untuk staf pengelola sistem dan 2. Adanya proses perpindahan data untuk memperoleh format yang sama dari tiap rumah sakit. ${ }^{18}$ Angelo menambahkan, selain melakukan pelatihan kepada staf, dalam pengelolaan sistem informasi kesehatan diperlukan panduan, seperti pedoman yang dapat berbentuk booklet, untuk membantu para pengelola sistem secara lebih mudah memahami sistem yang digunakan. ${ }^{19}$

Corine yang mengkaji kegiatan HIM pada sebuah rumah sakit yang ditinjau dari segi etik menyatakan bahwa, rumah sakit perlu memperhatikan beberapa hal seperti: 1. Bagaimana validitas data pasien, karena beberapa data yang dikelola mungkin hilang atau rusak, 2. Bagaimana kebijakan yang diberikan untuk akses ke data pasien lain, 3. Adanya personalisasi data seperti pengelompokkan data menurut keluarga dan sebagainya, 4. Bagaimana kebijakan jika data dikelola oleh jasa pengelola informasi dari luar rumah sakit. ${ }^{20}$ Terkait data yang disediakan untuk pengguna data, menurut Severin dkk rumah sakit dapat memutuskan apakah data yang dapat diakses hanya data hasil diagnosis pasien atau data lengkap dari proses awal pasien melakukan pendaftaran hingga proses perawatan selesai. ${ }^{21}$ Pada penelitian Tsung-Chih dan Zhen-Yu menyatakan bahwa, untuk mengembangkan kegiatan pelayanan kesehatan, sistem informasi medis harus memenuhi elemen: 1 . Adanya integrasi data antar departemen di dalam rumah sakit, 2. Adanya integrasi data antar rumah sakit, 3. Pengelolaan data medis dalam bentuk elektronik. ${ }^{22}$

Ross yang menjelaskan mengenai penerapan teknologi informasi dalam pelayanan kesehatan dapat membantu mempercepat pengumpulan data pasien antar instansi medis. ${ }^{23}$ Hal ini dapat dilakukan dengan berbagai cara seperti yang disampaikan oleh Ann dan John, melalui pengembangan aplikasi kesehatan berbasis mobile phone dapat membantu menyediakan akses terhadap data pasien secara lebih efektif. ${ }^{24}$ Penelitian Kenneth dkk yang mengkaji bagaimana aplikasi "invido" memungkinkan beragam sumber data medis dari berbagai rumah sakit dapat integrasi. Kenneth dkk menjelaskan elemen-elemen yang harus dipenuhi yaitu: 1. Rumah sakit sebagai penyedia layanan informasi kepada pasien, 2. Adanya pertukaran data pasien dari penyedia layanan kesehatan, 3. Pasien, peneliti, dan provider informasi sebagai pengguna, 4. Sistem aplikasi (invido), 5. Server aplikasi invido yang menjaga keamanan data. ${ }^{25}$

Penelitian Andrew mengenai dampak dari era digital terhadap kegiatan 
pelayanan kesehatan. Hal ini menuntut adanya pengelolaan data kesehatan pasien secara elektronik agar lebih mudah dikelola dan perlunya sistem untuk menjaga keamanan data pasien. ${ }^{26}$ Penelitian Joan dkk menjelaskan bahwa selain menyediakan sistem keamanan data pasien, menjaga privasi data pasien juga merupakan hal yang diperlukan. ${ }^{27}$ Penelitian Francois dan Ebere yang menyatakan, hal penting yang harus diperhatikan dalam pengelolaan data eletronik pasien yaitu: 1. Adanya pemanfaatan teknologi, 2. Adanya kebijakan penerapan EHR, 3. Adanya privasi data. ${ }^{28}$ Selanjutna penelitian Martha yang menjelaskan, pentingnya pertukaran data pasien yang dikelola secara elektronik akan dapat membantu memberikan pelayanan kesehatan pasien secara lebih baik. $^{29}$

Pada 23 penelitian tersebut memiliki berapa fokus kajian yang berbeda. Beberapa penelitian mengkaji kegiatan HIM berkaitan dengan privasi data pasien dan akses yang disediakan. ${ }^{8,14}$ Penelitian lain mengkaji penerapan HIM berkaitan dengan pemanfaatan aplikasi berbasis web dengan nama "invido" 25 dan pemanfaatan aplikasi berbasis mobile phone untuk menyediakan akses terhadap data kesehatan pasien secara lebih mudah. ${ }^{10}$ penelitian lain juga mengkaji pelaksanaan HIM dari segi etik dalam pengelolaan dan akses data pasien yang disediakan. ${ }^{20}$

Secara garis besar artikel ini membagi elemen-elemen yang diperlukan dalam pelaksaan HIM dari hasil kajian 23 penelitian tersebut ke dalam lima bagian. Yaitu: 1. HIM berkaitan dengan Sumber Daya Manusia (SDM), 2. HIM berkaitan dengan kebijakan dan kelembagaan, 3. HIM berkaitan dengan penerapan sistem, 4. HIM berkaitan dengan data dan pengelolaannya, 5. HIM berkaitan dengan akses dan integrasi data.

Dari 23 penelitian yang dikaji $31 \%$ dari penelitian tersebut membahas mengenai SDM sebagai faktor pendukung pelaksanaan pengelolaan informasi kesehatan pasien. Empat dari literatur tersebut menjelaskan bahwa pentingnya peran staf medis dalam membantu pengumpulan data pasien yang akan dikelola. ${ }^{7,25,8}$ Empat penelitian diantaranya menjelaskan bahwa rumah sakit perlu memperhatikan kemampuan staf pengelola sistem informasi dalam pemanfaatan sistem. Hal ini dapat dibantu dengan mengadakan pelatihan penggunaan sistem informasi kesehatan yang baik atau memberikan buku panduan penggunaan sistem. ${ }^{7,11,18,19}$

Berdasarkan 23 literatur yang dikaji $39 \%$ diantaranya membahas mengenai halhal yang berkaitan dengan kebijakan, organisasi dan kelembagaan sebagai elemen pendukung kegiatan HIM. Lima dari penelitian tersebut menjelaskan bahwa, dalam pelaksanaan pengelolaan informasi kesehatan pasien, diperlukan adanya kebijakan mengenai privasi dan sistem keamanan data pasien. ${ }^{8,14,26,27,28}$ Tiga dari literatur tersebut membahas mengenai pentingnya kebijakan dalam pengelolaan data terkait dengan kebijakan pengumpulan, pengelolaan, akses terhadap data, hingga kebijakan pengelolaan data berbasis elektronik. ${ }^{10,28,17}$ Dua dari literatur tersebut juga membahas mengenai pentingnya dukungan dari kepala instansi dalam pembuatan kebijakan mengenai pelaksanaan pengelolaan informasi kesehatan pasien. ${ }^{7,11}$ Satu literatur menambahkan adanya kebijakan mengenai anggaran yang harus dipersiapkan untuk mendukung kegiatan pengelolaan informasi kesehatan pasien dan perlu adanya struktur organisasi pada masingmasing instansi layanan kesehatan, yang berfungsi sebagai pengawas dalam pelaksanaan pengelolaan informasi kesehatan pasien yang terintegrasi. ${ }^{11}$

Dari 23 literatur tersebut $48 \%$ literatur membahas mengenai penerapan sistem dalam pelaksanaan HIM yang terintegrasi. Mengani pentingnya pemanfaatan sistem, empat dari literatur tersebut membahas mengenai pentingnya penerapan sistem dan pemanfaatan 
teknologi informasi untuk menunjang kegiatan pengelolaan informasi kesehatan pasien. ${ }^{10,18,28,13}$ Empat literatur juga membahas pentingnya penerapan sistem yang dapat mewakili semua instansi kesehatan yang berbeda, agar dapat menjadi sarana pendukung kegiatan HIM yang terintegrasi. Hal ini karena pada beberapa instansi kesehatan mungkin menggunakan sistem operasi pada komputer yang berbeda. ${ }^{8,11,16,22}$ Pada bidang ini dua literatur lainnya membahas mengenai model sistem yang dapat digunakan. Salah satu penelitian tersebut membahas mengenai model sistem berbasis web dengan nama "invido" 25 , satu lainnya membahas model penerapan sistem berbasis aplikasi mobile phone. ${ }^{24}$ Penelitian lain menjelaskan mengenai adanya satu sistem pusat dari HIM yang terintegrasi pada antar rumah sakit, sehingga sistem sentral ini dapat digunakan pada setiap anggota instansi kesehatan dan memudahkan proses berbagi data. ${ }^{17}$

$48 \%$ dari 23 literatur yang dikaji membahas mengenai data dan pengelolaannya dalam mendukung pelaksanaan pengelolaan informasi kesehatan pasien yang terintegrasi. Enam dari literatur tersebut menjelaskan mengenai pentingnya perubahan pengelolaan data pasien yang awalnya dilakukan secara konvensional untuk berpindah menuju pengelolaan secara elektronik. ${ }^{9,12,14,16,22,26}$ Tiga dari literatur tersebut menjelaskan bahwa perlu adanya format standar dari data-data yang dikelola pada masing-masing instansi kesehatan, sehingga dapat memastika data yang ada dapat digunakan oleh instansi lain yang membutuhkan. ${ }^{11,17,18}$ Dua literatur lainnya menjelaskan mengenai adanya personalisasi data, seperti data mungkin dapat dikelompokkan dalam beberapa bagian seperti keluarga, atau dari banyaknya informasi yang tersedia, informasi dapat ditampilkan dalam bentuk ringkasan. ${ }^{20,15}$
Dari 23 literatur tersebut $61 \%$ literatur membahas mengenai akses dan integrasi data dalam pelaksanaan HIM yang terintegrasi. 10 dari literatur tersebut mengkaji mengenai pentingnya integrasi data untuk dapat menyediakan akses terhadap data secara komprehensif kepada pasien, dari berbagai sumber informasi dari rumah sakit dimana mereka pernah dirawat. Selain itu adanya data yang terintegrasi juga dapat membantu para provider informasi (staf medis pada instansi layanan kesehatan) untuk memperoleh data pasien yang dibutuhkan. ${ }^{7,9,14,15,17,22,23,29,13,12 \quad \text { Dua }}$ literatur lainnya membahas mengenai akses yang disediakan dapat dilakukan melalui sebuah portal pada suatu aplikasi berbasis website atau aplikasi yang dapat diakses melalui mobile phone.,25 Dua literatur lainnya membahas mengenai data apa saja yang dapat diakses oleh pasien, apakah data keseluruhan atau data berkaitan dengan laporan diagnosis. ${ }^{15,21}$ Satu literatur lainnya membahas mengenai akses yang dapat dilakukan oleh pengguna lainnya, dalam hal ini yaitu pasien lain. ${ }^{20}$

\section{Model kegiatan Health Information Management (HIM) yang terintegrasi}

Banyak penelitian yang memberikan gambaran model yang dapat diterapkan dalam pengelolaan data dan informasi kesehatan pasien. Diantaranya yaitu model yang dijelaskan oleh Kenneth dkk mengenai bagaimana aplikasi berbasis website "invido" dapat membantu pasien untuk melakukan akses kepada data mereka dan membantu terciptanya proses pertukaran data dari masing-msiang penyedia data kesehatan pasien. Dari gambar pertama menjelaskan pasien, peneliti dan provider (tenaga medis rumah sakit) yang menjadi pengguna data. Pada gambar kedua menjelaskan proses pertukaran data dari provider data yang terdiri dari beberapa rumah sakit dan apoteker sebagai penyedia obat. Selain pengguna data, pada gambar 3 juga menjelaskan bahwa rumah sakit sebagai 
penyedia layanan kesehatan juga dapat melakukan akses terhadap data kesehatan pasien untuk membantu menyediakan layanan kesehatan secara lebih baik.
Aplikasi berbasis website ini dikelola oleh server yang akan membantu proses enkripsi data untuk menjaga keamanan data.

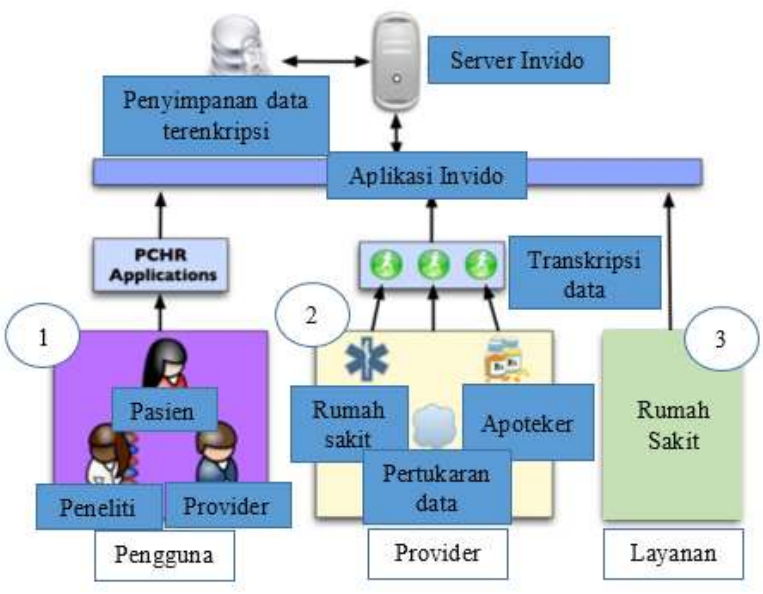

Gambar 1 Alur Integrasi Data Menggunakan Aplikasi Invido ${ }^{25}$

Model lain dari Hussain yang menggambarkan sebuah sistem dapat memungkinkan terjadinya pertukaran data kesehatan pasien. Pertukaran ini berasal dari beberapa petugas medis yang berasal dari staf radiologi, staf lab dan apoteker di bagian atas, dan para pengelola data pasien atau instansi layanan kesehatan lain di bagian kiri. Dalam kegiatan ini membutuhkan adanya kontrol dari pengelola sistem dan pengelola informasi kesehatan pasien di bagian bawah. Data yang tersedia ini dapat digunakan oleh para rumah sakit atau pengguna lain yang membutuhkan. Penggunaan data tersebut tentunya sesuai dengan kebijakan dari masing-masing instansi kesehatan.

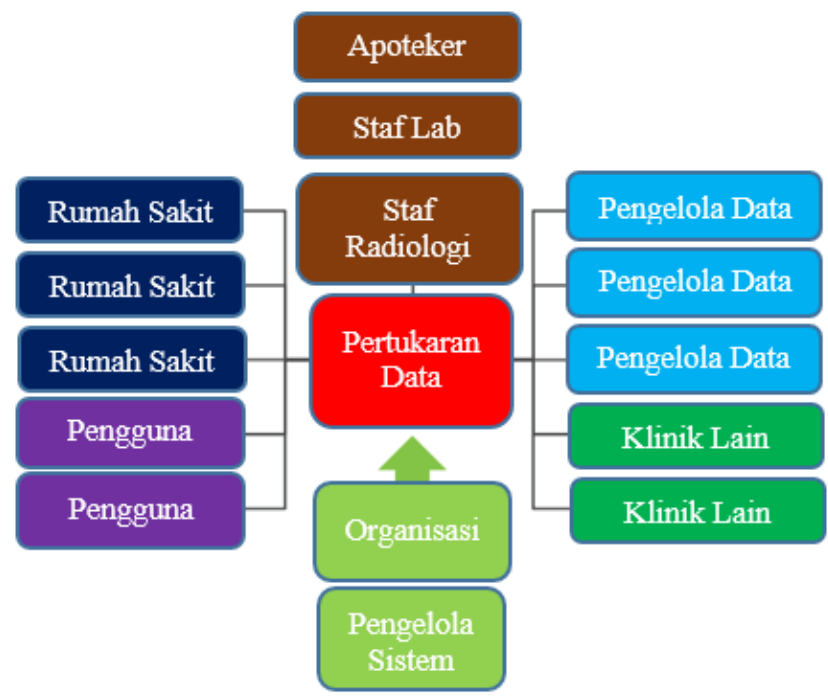

Gambar 2 Rangkaian Alur Pertukaran Informasi Kesehatan ${ }^{9}$

Kedua model tersebut menjelaskan mengenai pentingnya sebuah sistem aplikasi berbasi untuk memfasilitasi pertukaran data. Sistem tersebut dilengkapi dengan adanya server sebagai pengelola sistem, untuk melakukan enkripsi keamanan data pasien. Dalam pertukaran data pasien dilakukan oleh staf medis dari instansi kesehatan, pengelola data dari instansi kesehatan dan klinik lain. Data ini 
selanjutnya akan terkumpul pada server pengelola sistem, yang nantinya akan dapat diakses oleh pasien, staf medis dan

\section{Pembahasan}

Berdasarkan literatur yang dikaji dalam artikel ini, secara garis besar elemen yang diperlukan dalam penerapan HIM yang terintegrasi dapat dibagi ke dalam lima kompenen, yaitu: 1. Sumber Daya Manusia (SDM), 2. Kebijakan dan kelembagaan, 3. Penerapan sistem, 4. Data dan pengelolaannya, 5. Akses dan integrasi data.

\section{Sumber Daya Manusia (SDM),}

Sumber Daya Manusia
merupakan faktor penting implementasi pengelolaan informasi kesehatan pasien. ${ }^{7}$ SDM tidak hanya berkaitan dengan penyedia informasi, dalam hal ini SDM juga berkaitan dengan pengguna informasi, staf pengelola informasi dan staf pengelola sistem..$^{13,25}$

a. SDM sebagai staf pelayanan kesehatan dan provider informasi

SDM sebagai pelayanan kesehatan berasal dari staf medis pada sebuah rumah sakit. Selain melakukan pelayanan kesehatan, ${ }^{7}$ para staf medis ini juga berperan sebagai staf yang membantu untuk menentukan data mana yang penting untuk dikelola. ${ }^{25}$ Staf medis tersebut dapat berasal dari beberapa bidang pelayanan kesehatan seperti, staf farmasi, staf lab dan staf radiologi. ${ }^{13}$ Para staf medis ini dapat juga berperan sebagai provider data perawatan pasien, data hasil uji kesehatan, hingga catatan mengenai obat yang telah atau sedang dikonsumsi pasien. ${ }^{25}$

b. SDM sebagai pengelola data dan sistem Dalam pengelolaan sistem informasi kesehatan pasien, memerlukan adanya staff IT yang bertanggung jawab untuk mengelola sistem informasi kesehatan dan database pasien. ${ }^{13}$ Staf pengelola sistem informasi juga bertugas merawat sistem informasi. ${ }^{25}$ Sehingga kemampuan pengelola sistem informasi untuk dapat memfaatkan sisitem informasi dengan baik, merupakan hal sangat dibutuhkan. ${ }^{11}$ rumah sakit atau pengguna lain yang membutuhkan.

Oleh karena itu, adanya pelatihan untuk staff pengelola sistem merupakan hal yang penting. 7,18,19 Tidak hanya menyediakan pelatihan kepada staf pengelola sistem informasi, rumah sakit juga dapat menyediakan pedoman seperti booklet tentang cara pengelolan sistem informasi yang baik. ${ }^{11}$ Adanya hal ini rumah sakit akan memperoleh staf pengelola sistem yang terampil. ${ }^{13}$

c. SDM sebagai pengguna informasi

User dalam hal ini yaitu: pasien dan provider (staff medis). Bagi pasien, mereka dapat mengetahui informasi yang dibutuhkan untuk kesehatan mereka. Sedangkan bagi provider dapat membantu dalam pengambilan keputusan dalam pelayanan kesehatan. ${ }^{25}$

\section{Kebijakan dan kelembagaan}

Dalam kegiatan pengelolaan informasi kesehatan pasien yang terintegrasi, diperlukan adanya kebijkan mengenai pengelolan informasi. ${ }^{17}$ Adanya kebijakan dalam pengelolaan data akan dapat membantu untuk menentukan siapa saja yang dapat melakukan input data atau bagaimana standar pengelolaan data yang dilakukan. ${ }^{10}$ Selain menyediakan kebijakan mengenai pengelolaan data, rumah sakit juga harus memiliki kebijakan berkaitan dengan akses data yang disediakan. ${ }^{20}$ Rumah sakit dapat memutuskan apakah data yang dapat diakses hanya data hasil diagnosis pasien atau data lengkap dari proses awal pasien melakukan pendaftaran hingga proses perawatan selesai. $^{21}$

Hal penting lainnya yaitu kebijkan mengenai privasi dan keamanan data. ${ }^{27}$ Hal ini penting karena seluruh informasi pribadi dan medis pasien banyak dianggap sebagai informasi yang sensitif, rahasia dan pribadi. ${ }^{30}$ Banyak pasien khawatir mengenai bagaimana keamanan dan privasi data peronal mereka terutama hal yang berkaitan dengan gangguan mental 
dan seks. ${ }^{8}$ Sehingga diperlukan kebijakan privasi dan keamanan untuk menjaga data pasien. ${ }^{28}$ Untuk mengatasi hal ini pihak instansi dapat melakukan beberapa hal seperti melakukan sistem keamanan data dengan password yang mungkin hanya dapat dibuka oleh pasien atau petugas tertentu. ${ }^{30}$

Semua kegiatan tersebut tidak dapat terlaksana tanpa adanya dukungan kepala instansi sebagai pembuat kebijakan. Sehingga dukungan dari kepala rumah sakit merupakan hal penting untuk menciptakan pelaksanaan pengelolaan informasi kesehatan yang terintegrasi. ${ }^{11}$ Dukungan ini dapat dengan cara menyediakan anggaran untuk kegiatan sistem kesehatan yang terintegrasi. ${ }^{11}$

\section{Penerapan sistem}

Teknologi informasi yang terus berkembang turut membantu kegiatan pelayanan kesehatan. ${ }^{10}$ Diantaranya dapat digunakan untuk membantu memperoleh informasi kesehatan pasien terkini dengan waktu yang cepat dan membantu meningkatkan efisiensi pelayanan kesehatan $^{31}$ Oleh karena itu, banyak rumah sakit mulai menggunakan sistem informasi kesehatan yang digunakan untuk berbagai keperluan seperti, pengelolaan data pasien dan sebagainya. ${ }^{32}$ Adanya sistem informasi kesehatan, juga dapat membantu beberapa instansi layanan kesehatan untuk dapat menggabungkan semua data yang dibutuhkan oleh pembuat kebijakan, dokter dan pengguna layanan kesehatan. ${ }^{33}$ Sehingga pemilihan sistem informasi yang sesuai yang dapat mewakili semua instansi merupakan hal yang penting. ${ }^{16}$ Hal ini karena beberapa rumah sakit mungkin menggunakan sistem yang berbeda, ${ }^{8}$ atau beberapa pengguna informasi mungkin menggunakan beberapa operating sistem (OS) pada PC yang berbeda. Sehingga sistem yang dapat digunakan pada seluruh rumah sakit merupakan hal yang penting. ${ }^{16}$ Sistem yang diterapkan dapat bermacammacam. Kita dapat menerapkan sistem apliaksi berbasis website ${ }^{25}$ atau memanfaatkan sistem aplikasi berbasis mobile phone untuk lebih memudahkan dalam menyediakan akses informasi kesehatan. ${ }^{24}$

\section{Data dan pengelolaannya}

Data kesehatan pasien dapat berbentuk kertas ataupun berbentuk digital (elektronik). ${ }^{34}$ EHR dapat juga berupa catatan medis elektronik yang berisi demografi pasien, riwayat medis, obatobatan, dan informasi diagnostik dan lain sebagainya. $^{28}$ Bordoloi dan Nazrul menjelaskan bahwa pada EMR catatan medis pasien harus dapat disimpan dan diambil dalam format digital/ elektronik. ${ }^{35}$ Hal ini dapat dilakukan dengan cara beralih dari pengelolaan konvensional ke pengelolaan secara elektronik. ${ }^{16}$

Pada pengelolaan data kesehatan pasien rumah sakit juga harus memperhatikan validitas data pasien. Hal ini karena, terkadang informasi yang dikelola mungkin kurang lengkap karena hilang atau lain sebagainya. ${ }^{20}$ Beberapa hal lain juga harus diperhatikan dalam kegiatan pengelolaan informasi kesehatan pasien seperti bagaimana jenis data yang akan dikelola, apakah data-data tersebut hanya hasil alihmedia berbasis kertas ke bentuk elektronik atau data dalam bentuk gambar digital dan data yang telah diolah dalam bentuk video, dan lain sebagainya. ${ }^{30}$

Pada pengelolaan data kesehatan pasien, rumah sakit juga dapat mengelola data pasien dalam bentuk ringkasan ${ }^{15}$ atau data dikelompokkan pada hal tertentu, semisal data kesehatan sebuah keluarga. Sehingga hal ini dapat lebih memudahkan pasien atau staf medis untuk memahami informasi yang tersedia. ${ }^{20}$ Hal lain yang perlu diperhatikan yaitu adanya standar format data yang memastikan data dapat digunakan pada seluruh rumah sakit. ${ }^{11}$ Sehingga akan lebih baik jika data yang tersedia dapat ditransmisikan ke dalam format tertentu, semisal dalam bentuk microsoft exel. ${ }^{14,18}$

\section{Akses dan integrasi data}

Adanya sistem informasi kesehatan di rumah sakit dapat membantu penyedia layanan kesehatan untuk memperoleh 
informasi kesehatan pasien secara real time. ${ }^{33}$ Pada layanan informasi kesehatan pasien, rumah sakit dapat menetapkan apakah informasi yang disediakan merupakan data pasien secara keseluruhan semisal data keseluruhan dari awal pasien melakukan proses pendaftaran hingga pemeriksaan kesehatan selesai, atau hanya beberapa data seperti hasil diagnosis pasien. ${ }^{15,21}$

Hal yang penting yaitu bagaimana akses terhadap data dapat disediakan secara komprehensif, pada seluruh instansi kesehatan. Atas dasar ini perlu adanya integrasi data kesehatan pasien pada beberapa rumah sakit. ${ }^{11}$ Dengan melakukan pengelolaan informasi kesehatan pasien yang terintegrasi, pasien dan staf medis akan dapat melakukan akses ke record pasien, dimanapun dan kapanpun dibutuhkan secara cepat. $^{28,23}$
Keuntungan lain dari adanya integrasi data yaitu, rumah sakit dapat meningkatkan kegiatan berbagi data kepada pasien. ${ }^{12}$

Unutk mengintegrasikan informasi kesehatan pasien, dapat dilakukan dengan bermacam-macam cara, seperti mengintegrasikan sistem informasi pada beberapa rumah sakit, melalui sistem pengelolaan informasi kesehatan tersentral. ${ }^{17}$ Dalam pelaksanaannya kita dapat memanfaatkan aplikasi atau software tertentu. $^{28}$ Untuk menyediakan akses informasi, sistem ini dapat menyediakan sebuah portal, sehingga hanya pengguna tertentu yang dapat melakukan akses terhadap informasi kesehatan pasien. ${ }^{7}$

Atas dasar ini penulis memiliki usulan model pengelolaan informasi kesehatan pasien yang terintegrasi sebagai berikut:

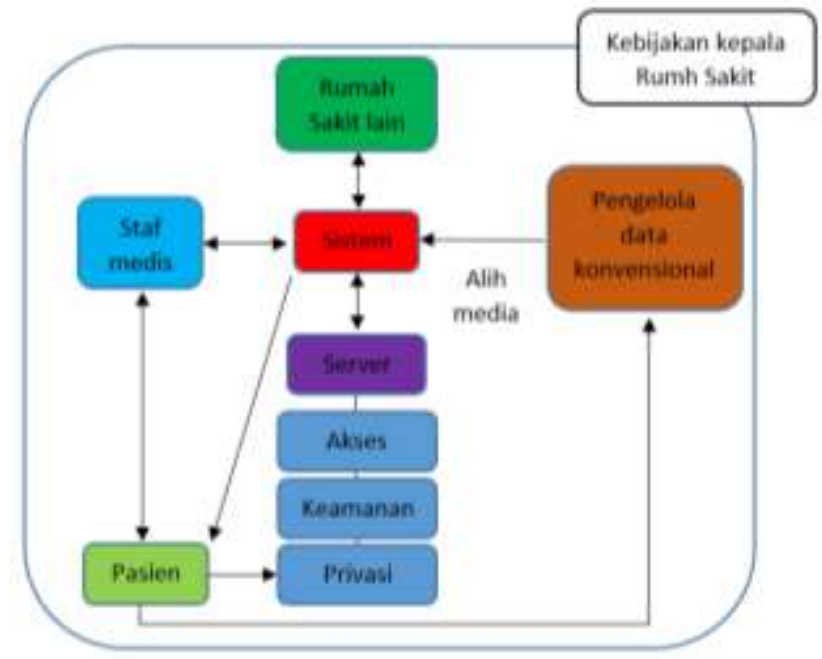

Gambar 3 Alur Pengelolaan dan Pertukaran data dalam HIM yang Terintegrasi

Pada gambar 3 menjelaskan mengenai alur penerapan HIM pasien yang terintegrasi. Pada alur pertama menjelaskan mengenai asal informasi kesehatan pasien yang dapat diperoleh dari staf medis, rumah sakit lain dan data konvensional yang telah dialih media. Semua data ini akan terkumpul pada sistem HIM yang dikelola oleh server, yang menjadi admin pada masingmasing rumah sakit. Sebagai pengelola sistem, server akan mengatur akses dan keamanan informasi data pasien. Terkait privasi informasi, data setiap pasien ini hanya akan diperbolehkan diakses untuk membantu pelaksanaan pelayanan kesehatan dari pasien terkait, sehingga informasi seorang pasien yang akan digunakan untuk pasien lain, harus memperoleh ijin dari pemilik informasi. Staf medis sebagai petugas layanan kesehatan dapat mengakses informasi pasien untuk membantu dalam memberian layanan kesehatan kepada pasien. Rumah sakit lain juga dapat melakukan akses terhadap data pasien 
atau menjadi elemen dalam pertukaran informasi kesehatan pasien. Hal ini tentu tidak akan berjalan tanpa adanya kebijakan dari masing-masing kepala rumah sakit.

\section{Simpulan}

Berdasarkan hasil dan pembahasan, dapat disimpulkan bahwa elemen yang diperlukan dalam penerapan HIM yang terintegrasi dapat dibagi ke dalam lima kompenen yaitu: 1 . Sumber Daya Manusia (SDM), yang berperan sebagai staf pelayanan kesehatan dan provider informasi, pengelola data dan sistem dan pengguna informasi. 2. Kebijakan dan kelembagaan. Kebijakan ini terkait dengan pengelolan informasi, akses data, privasi serta keamanan data dan kebijakan kepala instansi untuk mendukung pelaksanaan HIM yang terintegrasi, diantaranya dengan memberikan anggaran. 3. Penerapan sistem. Sistem ini harus disesuaikan dan dapat digunakan pada seluruh instansi yang menjadi anggota HIM yang terintegrasi dan memudahakan pasien untuk melakukan akses informasi. 4. Data dan pengelolaannya. Pada pelaksaan HIM yang terintegrasi, semua data pasien akan dikelola dalam format elektronik. Data tersebut dapat juga dikelola dalam bentuk ringkasan sehingga memudahkan pasien dan tenaga medis untuk menggunakannya. Hal yang penting dalam pengelolaan data pasien yaitu adanya format data general yang dapat digunakan seluruh rumah sakit. 5. Akses dan integrasi data, diperlukan untuk memudahakn para pasien dan petugas medis dalam memperoleh data pasien secara real time. Data yang disediakan dapat merupakan data pasien secara keseluruhan atau data tertentu, tergantung dari kebijakan rumah sakit dan ijin dari pasien. Hal penting yaitu bagaimana data kesehatan seorang pasien dari berbagai rumah sakit dapat terintegrasi. Hal ini dapat dilakukan dengan mengintegrasikan data pada sebuah sistem pengelolaan informasi kesehatan.

Adapun model dalam pengelolaan informasi kesehatna pasien yang terintegrasi harus memungkinkan terciptanya pertukaran data kesehatan pasien yang dikelola beberapa staf medis, para pengelola data pasien dan instansi rumah sakit lain. Dalam kegiatan ini membutuhkan adanya kontrol dari server sebagai pengelola sistem dan pengelola informasi kesehatan pasien, yang menjaga keamanan informasi. Server juga akan menentukan data mana dan siapa yang dapat melakukan akses. Sistem yang disediakan dapat berupa aplikasi berbasi website.

\section{Daftar Pustaka}

1. World Health Organization, Global Observatory for eHealth. Management of Patient Information: Trends and Challenges in Member States: Based on The Findings of The Second Global Survey on eHealth Seri ke-6. Geneva: Global Observatory for eHealth Series; 2012.

2. Royal College of Nursing, Policy and International Departement. Personal Health Records and Information Management Helping Patients, Clients and Their Parents/ Carers to Make The Most of Health Information. London: Royal College of Nursing; 2014.

3. Smith E, Macdonald R. Managing Health Information During Disasters. Health Inf Manag J. 2006;35(2):143-7.

4. Francois M, Monique J, Obisike EE. Accelerating the National Implementation of Electronic Health Records in Canada. Eur Sci J. 2016;12(15):65-80.

5. Edaibat EA, Dever J, Tanju B, Stuban SMF. A System Dynamics 
Simulation Modeling: Health Information Exchange Adoption in The U.S. Healthcare System. Proceedings of the 2014 Winter Simulation Conference; 2014; Washington DC, USA. USA: George Washington University; 2014.

6. Shah JR, Murtaza MB, Opara E. Electronic Health Records: Challenges and Opportunities. J Int Tech Inf Manag. 2014;23(3-4): 189204.

7. Sharon Silow-Carroll, Jennifer N. EdwardS, dan Diana Rodin. Using Electronic Health Records to Improve Quality and Efficiency: The Experiences of Leading Hospitals. Common Wealth Fund pub. $2012 ; 17$.

8. Claudia Pagliari, Don Detmer dan Peter Singleton. Potential of electronic personal health records. Analysis. 2007;335.

9. Ashish K. Jha, David Doolan, Daniel Grandt, Tim Scott dan David W. Bates. The use of health information technology in seven nations. Int.J Med. Informatics. 2008;77:848-854.

10. Stephen T. Parente dan Jeffrey S. McCullough. Health Information Technology And Patient Safety: Evidence From Panel Data. Affairs. 2009; 28(2):357-360.

11. Esther Suter, MSW, Nelly D. Oelke, RN, MN, Carol E. Adair, BA, MSc, dan Gail D. Armitage, BA, MA. Ten Key Principles for Successful Health Systems Integration. Healthc Q. 2009.

12. Jennifer E. Cahill, Terri $S$. Armstrong dan Mark R. Gilbert. Personal health records as portal to the electronic medical record. J Neur. 2014;117:1-6.

13. Hussain K, Babalghith AO. Health Information Management \& Technology: A New Era of
Transforming Healthcare. Int Res. 2013; 2 (1):152-64.

14. Oliver Heinze, Markus Birkle, Lennart Köster and Björn Bergh. Architecture of a consent management suite and integration into IHE-based regional health information networks. BioMed. Med. Informatics. 2011;11(5).

15. Dean F. Sittig, Christopher A. Longhurst, Elise Russo, dan Hardeep Singh. Safe and Effective Care for Adults and Children. Health Inf. 2016;4: 21-38.

16. James $T$. Ingram. The Journey to Usability: A Vendor's Perspective. Health inf. 2016;4:39-49.

17. Muhammad Suleman Qazi, Moazzam Ali. Health Management Information System utilization in Pakistan: Challenges, pitfalls and the way forward. BioSci. 2011; $5(6): 245-254$.

18. Vincent Micheal Kiberu, Joseph KB Matovu, Fredrick Makumbi, Carol Kyozira, Eddie Mukooyo dan Rhoda K Wanyenze. Strengthening district-based health reporting through the district health management information software system: the Ugandan experience. Med. Inf. 2014;(14).

19. Angelo S Nyamtema. Bridging the gaps in the Health Management Information System in the context of a changing health sector. BioMed Inf. 2010;36(10).

20. Corine Mouton Dorey. Rethinking the ethical approach to health information management through narration: pertinence of Ricœur's 'little ethics'. Med. Health Care and Philos. 2016; 19:531-543.

21. Severin Kabakamaa, Sospatro Ngallabaa, Richard Mustoc, Stephanie Montesanti, Eveline Konje A, dan Coleman Kishamawe. Assessment of Four common underfive children illnesses: Routine Health Management 
Information System data for decision making at Ilemela. 2016;93:85-91.

22. Tsung-Chih Hsiao, Zhen-Yu Wu \& Yu-Fang Chung, Tzer-Shyong Chen dan Gwo-Boa. HorngA Secure Integrated Medical Information System. J Med Syst. 2012;36:310313.

23. Ross Koppel. Great Promises of Healthcare Information Technology Deliver Less. Health inf. 2016;4:101-26.

24. Ann O'Brien dan John E. Mattison. Emerging Roles in Health and Healthcare. Health inf. 2016;4:199218.

25. Kenneth D Mandl, William W Simons, William CR Crawford dan Jonathan M Abbett. Software Indivo: a personally controlled health record for health information exchange and communication. BioMed Central. 2007;25(7).

26. Andrew R. Watson. Impact of the Digital Age on Transforming Healthcare. Health inf. 2016;4: 219234.

27. Joan M. Kiel, Frances A. Ciamacco dan Bradley T. Steines. Privacy and Data Security: HIPAA and HITECH. Health inf. 2016;4:437452.

28. Francois M, Monique J, Obisike EE. Accelerating the National Implementation of Electronic Health Records in Canada. Eur Sci J. 2016;12(15):65-80.

29. Martha Jean Minniti, Thomas R. Blue, Diane Freed, dan Sasha Ballen. Patient-Interactive Healthcare Management, a Model for Achieving Patient Experience Excellence. Health inf. 2016;4:257282.

30. Fatt OK, Zain AZMd. Implementation and Issues Concerning Electronic Healthcare Records. J Healthcare Comm. 2016;1(3):1-4.
31. Ammenwerth E, Graber S, Herrmann G, Burkle T, Konig J. Evaluation of Health Information Systems-Problems and challenges. Int J Med Informatics. 2003:1-11.

32. Ngafeeson M. Healthcare Information Systems: Opportunities and Challenges. Inf Sci Ref. 2014;(2):332-41.

33. Sinha RK. Impact of Health Information Technology in Public Health. Sri Lanka J Biomed Informatics. 2010;1(4):223-36.

34. Kiyumi RA, Walker S, Tariq A, FitzGerald G. Health Information Management Professionals. 2017.

35. Bordoloi P, Islam N. Knowledge Management Practices and Healthcare Delivery: A Contingency Framework. Elec J Know Manag. 2012;10(2):11020. 